\title{
A Comparative Study of Different Types of Thyme Essential oils Against Streptococcus pyogenes to Determine their Biochemical and Antimicrobial Properties
}

\section{MUAZZAM SHERIFF MAQBUL ${ }^{1}$, YUMNA ABDULMALEK BOKHARI ${ }^{2}$, SAMAHER GUMAAN BASALIB ${ }^{2}$, SHADEN NABIL ALHELALI ${ }^{2}$, BASHAIR MOHAMMED MAHMOUD OMAR ${ }^{2}$, AEJAZ A. KHAN ${ }^{3}$, S. M. SHAKEEL IQUBAL ${ }^{3 *}$ and TASNEEM MOHAMMED ${ }^{3}$}

${ }^{1}$ Faculty of Microbiology and Immunology, Ibn Sina National College of Medical Sciences, Al-Mahjar

Street: 31906, Jeddah-21418, Kingdom of Saudi Arabia.

${ }^{2}$ Medicine Program, Ibn Sina National College of Medical Sciences, Al-Mahjar Street: 31906, Jeddah-21418, Kingdom of Saudi Arabia.

${ }^{3}$ Department of General Science, Ibn Sina National College of Medical Sciences, Al-Mahajar Street: 31906, Jeddah-21418, Kingdom of Saudi Arabia.

${ }^{*}$ Corresponding author E-mail: shakeeliqubal@gmail.com

http://dx.doi.org/10.13005/ojc/360202

(Received: January 21, 2020; Accepted: March 01, 2020)

\begin{abstract}
A comparative study of different types of thyme essential oils against Streptococcus pyogenes to determine their biochemical and antimicrobial properties along with the bacteriostatic and bactericidal effect as it has proven one of the better alternative for the abuse of antibiotics with no side effects. The gaseous contact of these oils is an ancient and forgotten methods in the modern world and this research is an attempt to resurrect the ancient technique to benefit the mankind as the alarming WHO reports suggests that the world is running out of antibiotics due to antibiotic abuse causing mutant species. This research was performed on the reflection of WHO reports. The biochemical studies of the three thymes reveals the presence of alkaloids, reducing sugar, iodine, steroids and phenols which serves as a major factor in combating the respiratory tract illness. The antimicrobial properties of different types of thyme essential oils against $S$. pyogenes to determine their bacteriostatic and bactericidal effect was carried out using standard microbiological antibiotic assay such as Kirby bauer disc diffusion method, Minimum Inhibitory Concentration (MIC) and Minimum Bactericidal Concentration (MBC) techniques. The result of this attempt was satisfactory especially with the Jordanian thyme essential oil and a survey was conducted over a sample of 500 participants to determine the awareness of antibiotic abuse with the benefits of thyme essential oils. The significantly important biochemical tests were performed to determine the phytochemical compounds present in the thyme to understand its antimicrobial mechanism. The observation along with results for the work is fully documented statistically for your perusal.
\end{abstract}

Keywords: Biochemical properties, Antimicrobial susceptibility testing, Thyme Essential oil, Respiratory tract pathogens.

This is an Open Access article licensed under a Creative Commons license: Attribution 4.0 International (CC- BY). Published by Oriental Scientific Publishing Company @ 2018 


\section{INTRODUCTION}

Essential oils produced by plants are used as an ethical medicine for colds by ancient traditional method for respiratory tract infections ${ }^{1-2}$. In the medicinal field, acute and chronic bronchitis are treated by inhalation therapy of essential oils. Maintenance of ventilation, drainage of the sinuses and production of respiratory tract fluid increased with inhalation of vapors of essential oils which had an anti inflammatory reaction on the trachea and it reduces asthma ${ }^{3-6}$. Essential oils are known for their antimicrobial effect which has been tested in a lysogeny broth. Standardized evaluation of the essential oil vapor was first described by Maruzzella et al., \& Kienhoiz utilising an inverted Petri dish technic ${ }^{7-9}$. The technic is carried out by using a volatile compound which is placed in a cup or a paper disc and it is exposed to the inverted agar medium which is then inoculated with test strains at about a $5 \mathrm{~mm}$ distance. This technique was convenient and had been used by subsequent researchers ${ }^{7-11}$. Under these circumstances, the airspaces were too tiny to evaluate the vapor concentration of essential oil. Airtight box of one litre air capacity for the measurement of vapor activity was used ${ }^{12-13}$. Assessment of cinnamon oil versus respiratory tract mycoses have been noted. But, no report explaining the vapor effect of essential oils versus major bacterial respiratory tract pathogens. At room temperature, in opposition to antibiotics, essential oils are extremely volatile. Due to that, we looked into a potential character for these oils to be used as inhalation treatment, $\&$ therefore we analysed the antimicrobial activity of a large variety of them against, Streptococcus pyogenes by gaseous contact by Kirby-Bauer method and their dilutions were measured using Minimum Inhibitory Concentration method with Bactericidal effects by Minimum Bactericidal Concentration method. The significantly important biochemical tests were performed to determine the phytochemical compounds present in the thyme to understand its antimicrobial mechanism against the respiratory pathogens. This work was carried out to challenge the efficacy of so many synthetic antibiotic against the respiratory pathogens such as $S$. pyogenes which has failed in the treatment due to the abundant use of drugs ${ }^{14-15}$. There are plenty of natural essential oils available in the biosphere and one such is thyme essential oils ${ }^{14-16}$. The major goal of this work is to study the comparative investigation of different types of thyme essential oils efficacy towards Streptococcus pyogenes to determine their biochemical and antimicrobial properties to evaluate the bacteriostatic and bactericidal effect.

\section{MATERIAL AND METHODS}

\section{Materials and reagents}

Types of thyme essential oil, throat swab sample from a patients, standard microbial strains and different types of Hi-Media culture plates used and biochemical reagents were procured from Sigma-Aldrich chemicals (USA).

\section{Isolation and Purification of Streptococcus pyogenes}

The sample from the patient was collected employing throat swab technique and was inoculated on a sterile blood agar plate by streak plate method and incubated for $24 \mathrm{~h}$ at room $37^{\circ} \mathrm{C}$ and visible beta-hemolytic colonies were isolated ${ }^{14-15}$.

A loopful of colony was taken and Gram's stain was performed to observe the Gram-positive violet-colored cocci in the form of chains.

A loopful of culture was mixed with a drop of hydrogen peroxide and no bubbles were observed which indicated the absence of catalase enzyme and is a confirmatory test to differentiate the Streptococcus from other cocci.

\section{Thyme essential oil preparation}

Three types of thyme essential oils Jordanian, Palestinian and Syrian were prepared by dissolving $100 \mathrm{~g}$ of each thyme leaves in $500 \mathrm{~mL}$ distilled water and boiled at $100^{\circ} \mathrm{C}$ for about $1 \mathrm{~h}$ and filtered using filter paper to get the thyme extract $1^{4,16-19}$.

\section{Bio-chemical analysis of the thyme extract}

The biochemical properties analysis of the thyme extract was determined by the following methodologies ${ }^{16,20}$. 
1) Fehling's test, $2 \mathrm{~mL}$ of Fehling's $A$ and $B$ reagents were mixed with the thyme extract in a test tube and heated slightly to observe brick red color indicating the presence of reducing sugar.

2) lodine test, The presence of iodine in the thyme extract was determined by the addition of $2 \mathrm{~mL}$ of iodine solution to the thyme extract which results in the positive purple colored test.

3) Salkowski's test, The thyme extracts were mixed with $2 \mathrm{~mL}$ of chloroform along with $2 \mathrm{~mL}$ of concentrated sulphuric acid in a test tube and gently shaken to observe a reddish brown color which indicates the presence of steroids.

4) Ferric test, Thyme extract was boiled with $10 \mathrm{~mL}$ of water in a test tubes. A few drops of ferric chloride was added to the $10 \mathrm{~mL}$ of heated yeast extract in a test tube to observe a blue black coloration which indicates the presence of phenol.

5) Wagner's test was performed by treating the thyme extracts with lodine and Potassium iodide results in a reddish brown precipitate indicates the presence of alkaloids ${ }^{16,17,20}$.

\section{Antimicrobial Susceptibility Testing}

The following three methodologies were employed to determine the antimicrobial susceptibility testing for the thyme essential oil against Streptococcus pyogenes ${ }^{14-15}$.

\section{Kirby-Bauer method-Disc diffusion method}

The disk diffusion method (Kirby-Bauer) is more suitable for routine testing in a clinical lab where a large number of isolates are tested for susceptibility to antimicrobial effects ${ }^{14-16}$. A standardized antibiotic disc was prepared and incubated at $37^{\circ} \mathrm{C}$ soaked overnight in the thyme essential oils of each thyme respectively and incorporated on Mueller-Hinton agar and incubated at $37^{\circ} \mathrm{C}$ for $24 \mathrm{~h}$ to determine the drug susceptibility of microorganisms isolated from infectious organisms. This method allows the rapid determination of the efficacy of the antimicrobial properties by measuring the diameter of the zone of inhibition that results from diffusion of the agent into the medium surrounding the disc. The comparative study was performed by incorporating all the three essential oil disc in a single Mueller-Hinton agar plate by repeating the procedure and results were observed and recorded.

\section{Minimum Inhibitory Concentration-Tube dilution} method (MIC)

Minimum Inhibitory Concentration (MIC) was used ${ }^{16-18}$ to determine the lowest concentration of thyme essential oil to inhibit the visible growth of a Streptococcus pyogenes after overnight incubation at $37^{\circ} \mathrm{C}$ in a incubator where a serial dilution of the respective thyme essential oil is prepared and inoculated with the inoculum The MIC values were observed with the last tube with turbidity determining the bacteriostatic effect of the respective essential oils and were recorded.

\section{Minimum Bactericidal Concentration Method (MBC)}

The minimum bactericidal concentration (MBC) was performed ${ }^{17-19}$ to determine the lowest concentration of all the three essential oils required for the bactericidal effect on Streptococcus pyogenes by dividing the blood agar into six portions representing each dilution of MIC. The sample from each dilution was inoculated on each designated portions for the respective dilutions for all the three essential oil MIC dilutions separately. The plates were incubated at $37^{\circ} \mathrm{C}$ for $24 \mathrm{~h}$ to determine the bactericidal activity of the respective thyme essential oils against the bacterium.

\section{RESULTS AND DISCUSSION}

Table 1, shows the results of the KirbyBauer Disc Diffusion method of the three types of thyme essential oils used (Syrian, Jordanian and Palestinian) which shows that Jordanian has the highest diameter which indicates that this thyme will be more effective to use against Streptococcus pyogenes among the others ${ }^{16}$. Fig. 1 shows a bar chart of the Kirby-Bauer Disc Diffusion test of the three types of thyme essential oils used. All the thyme essential oils examined exhibited antibacterial activity. Among the three types of thyme essential oils used the Jordanian thyme essential oils showed the highest activity then comes the Palestinian then Syrian thyme essential oils. Fig. 2 shows the pictures of the Kirby-Bauer disc diffusion test preformed for each thyme individually as well as all of the three thymes together in one agar plate, which clearly shows that the Jordanian thyme essential oil is the most effective and has the best results. 
Table 1: Kirby-Bauer disc diffusion results

\begin{tabular}{lccc}
\hline \multicolumn{4}{c}{$\begin{array}{c}\text { Kirby - Bauer Disc Diffusion } \\
\text { Zone of inhibition measurement }\end{array}$} \\
\hline & Syrian & Jordanian & Palestinian \\
\hline S. pyogenes Sample-1 & $15 \mathrm{~mm}$ & $31 \mathrm{~mm}$ & $21 \mathrm{~mm}$ \\
S. pyogenes Sample-2 & $14 \mathrm{~mm}$ & $30 \mathrm{~mm}$ & $23 \mathrm{~mm}$ \\
S. pyogenes Sample-3 & $16 \mathrm{~mm}$ & $29 \mathrm{~mm}$ & $24 \mathrm{~mm}$ \\
\hline
\end{tabular}

Kirby-Bauer Disc Diffussion Method

-Syrian Jordanian Palestinian

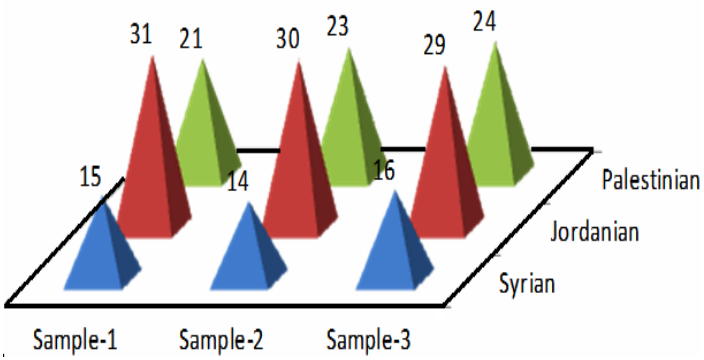

Fig. 1. Kirby-Bauer disc diffusion bar chart
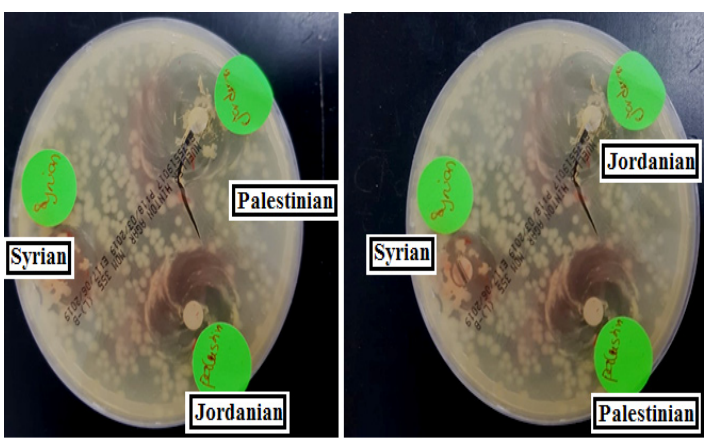

Fig. 2. Kirby-Bauer disc diffusion taken during the process

Table 2 shows the Minimum Inhibitory Concentration (MIC) of all three thymes with concentration that ranges from 1:2, 1:4,1:8, 1:16 1:32 and 1:64. MIC is defined as the lowest concentration of antimicrobial agents that is bacteriostatic meaning it prevents the visible growth of bacteria. Turbidity usually will show on the MIC test tubes and those who don't show turbidity are those concentration that is recorded ${ }^{15-16}$. For Syrian MIC, turbidity showed last on test tube with value 1:64 so test tube with value $1: 64$ is the one with no turbidity and that is recorded. As for Jordanian, no turbidity showed on the test tube with value $1: 4$ and lastly, for Palestinian, no turbidity was clear on the test tube with value 1:8. Fig. 3 is the MIC.

This method allows the rapid determination of the efficacy of a drug by measuring the diameter of the zone of inhibition that results from diffusion of the agent into the medium surrounding the disc. Fig. 4, 5 and 6 all show pictures of the MIC for all 3 types of thyme and those test tubes that does not have turbidity.

Table 2: Minimum Inhibitory Concentration (MIC) used for each thyme

\begin{tabular}{cccc}
\hline \multicolumn{3}{c}{ MIC } \\
\hline $\mathrm{dl} / \mathrm{ml}$ & Syrian & Jordanian & Palestinian \\
\hline $1: 2$ & Turbid & Turbid & Turbid \\
$1: 4$ & Turbid & No-turbidity & Turbid \\
$1: 8$ & Turbid & No-Turbid & No-Turbid \\
$1: 16$ & Turbid & No-turbidity & No-turbidity \\
$1: 32$ & Turbid & No-turbidity & No-turbidity \\
$1: 64$ & No-turbidity & No-Turbid & No-Turbid \\
\hline
\end{tabular}

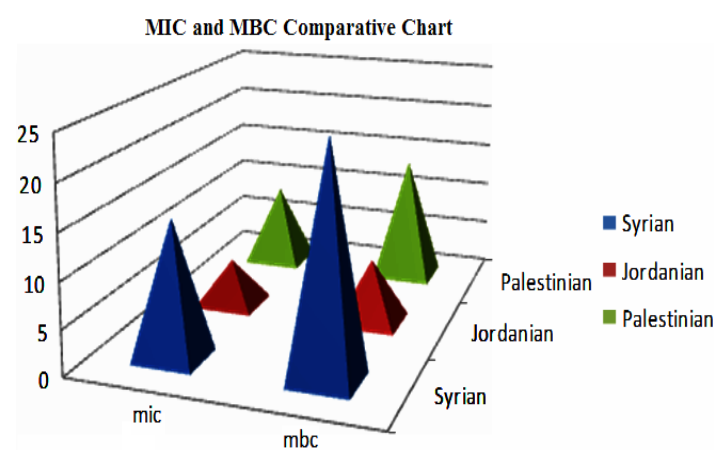

Fig. 3. Comparative chart of Minimum Inhibitory Concentration (MIC) with Minimum Bacterial Concentration (MBC) for each thyme

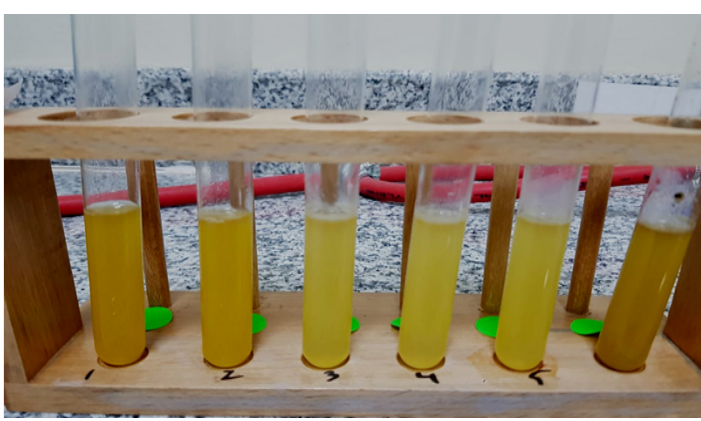

Fig. 4. Minimum Inhibitory Concentration for Jordanian thyme

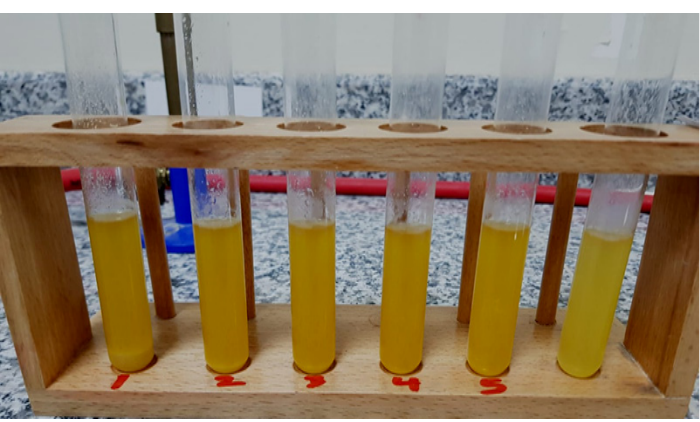

Fig. 5. Minimum Inhibitory Concentration for Syrian thyme 


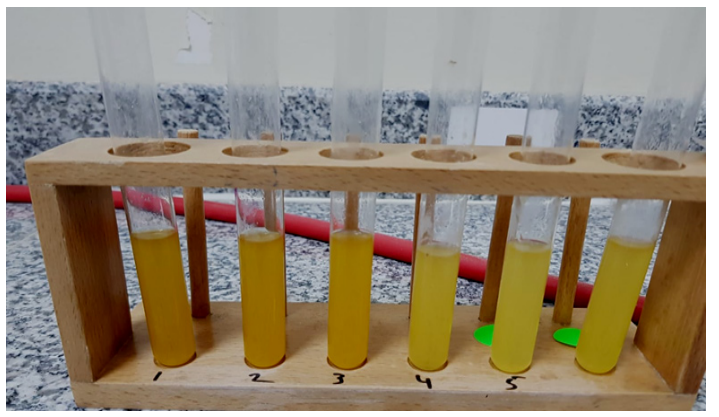

Fig. 6. Minimum Inhibitory Concentration for Palestinian thyme

Table 3, shows the Minimum Bacterial Concentration (MBC) of the three types of thyme. $\mathrm{MBC}$ is the lowest concentration of an antibacterial agent required to kill a particular bacterium which is determined from the MIC by culturing the agar plates that contain the Streptococcus pyogenes. Testing the thymes from the MIC with concentration that ranges from 1:2, 1:4,1:8, 1:16 1:32 and 1:64 show that all of the ranges have growth and it is illustrated in Figure 7.

Figure 3 shows that all three types of thyme are equal in the Minimum Bacterial Concentration 16-18 of 1.08 .

Table 3: Minimum Bacterial Concentration (MBC) used for each thyme

\begin{tabular}{cccc}
\hline & & MBC values \\
\hline $\mathrm{dl} / \mathrm{ml}$ & Syrian & Jordanian & Palestinian \\
\hline $1: 2$ & Growth & Growth & Growth \\
$1: 4$ & Growth & Growth & Growth \\
$1: 8$ & Growth & Growth & Growth \\
$1: 16$ & Growth & Growth & Growth \\
$1: 32$ & Growth & Growth & Growth \\
$1: 64$ & Growth & Growth & Growth \\
\hline
\end{tabular}

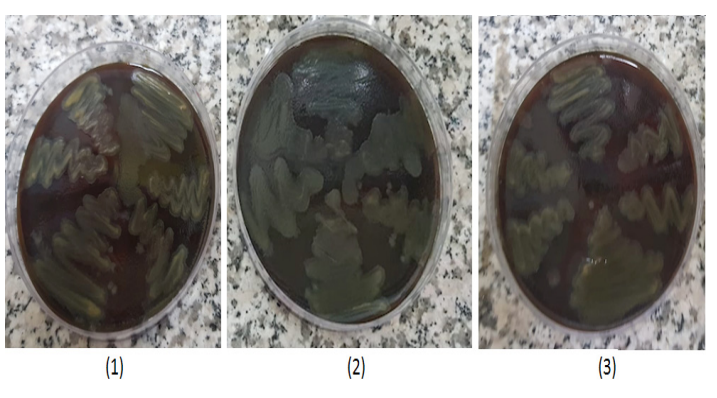

Fig. 7. Minimum Bacterial Concentration for (1) Palestinian (2) Jordanian (3) Syrian thymes

Table 4 shows a comparative chart of different types of thyme essential oil against Streptococcus pyogenes for all tests performed (Kirby-Bauer, MBC, MIC). Fig. 9 is a pie chart of different types of thyme essential oil against Streptococcus pyogenes which illustrates that Jordanian thyme accounts for $50 \%$ compared to Palestinians with $33 \%$ and Syrian with $17 \%$.

A questionnaire that was carried out among the Saudi Community in the month on September that is aimed at understanding whether the community is aware and uses thyme essential oil against respiratory tract pathogens as well as general important questions about antibiotics that include; allergy from antibiotic, whether the doctor requested any test before administering any antibiotics and lastly is they are satisfied with the course of antibiotics. Three tables are constructed.

Table 4: Comparative chart of different types of thyme Essential oil against Streptococcus pyogenes

\begin{tabular}{lccc}
\hline Thyme/Test & $\begin{array}{c}\text { Test No.1 } \\
\text { Disc Diffusion }\end{array}$ & $\begin{array}{c}\text { Test No.2 } \\
\text { MIC }\end{array}$ & $\begin{array}{c}\text { Test No.3 } \\
\text { MBC }\end{array}$ \\
\hline Syrian & $15 \mathrm{~mm}$ & $>1: 64 \mathrm{dl} / \mathrm{mL}$ & $>1: 64 \mathrm{dl} / \mathrm{mL}$ \\
Jordanian & $31 \mathrm{~mm}$ & $1: 4 \mathrm{dl} / \mathrm{mL}$ & $>1: 64 \mathrm{dl} / \mathrm{mL}$ \\
Palestinian & $23 \mathrm{~mm}$ & $1: 8 \mathrm{dl} / \mathrm{mL}$ & $>1: 64 \mathrm{dl} / \mathrm{mL}$ \\
\hline
\end{tabular}

Efficacy of different types of thyme

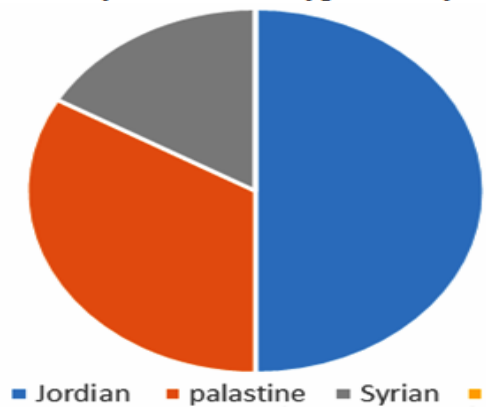

Fig. 8. Pie chart of different types of thyme essential oil against Streptococcus pyogenes

Table 5 revolved around the general characteristics of the respondent out of $(n=500)$ $44.4 \%$ were males and $55.6 \%$ were females. Age ranged from 17-65 with mean (Std. deviation) of 6.21. $33 \%$ reported that they occasionally have a sore throat which is the highest. $5.8 \%$ reported having an allergy from antibiotics and $94.2 \%$ are not allergic. A dreadful $72.2 \%$ of respondents reported that the doctor did not request doing any test before starting an antibiotic course which could be fatal since testing before administrating an antibiotic therapy is a key factor in administrating the most suitable antibiotic and $60.8 \%$ reported being satisfied with the course of antibiotics administered. Table 6 revolves around 
general questions about side effects after antibiotics administration, vaccination as well as trying a natural remedy for sore throat. It found out that after administrating antibiotics $28.4 \%$ notices side effects like diarrhea while $71.6 \%$ did not notice. $75.6 \%$ did not suffer from sore throat infection after vaccination and $24.4 \%$ did suffer from sore throat infection. $69.2 \%$ tried or thought of any natural remedy for sore throat while $30.8 \%$ did not. Table 7 which is the last table revolves around general characteristics for thyme. Questions include if thyme essential oil has been used for treatment of sore throat, if side effects are noticed after treatment of sore throat with thyme essential oil and lastly preferable thyme used. $16.4 \%$ of respondent used thyme essential oil for treatment of sore throat and $83.6 \%$ did not use. $21.8 \%$ found side effects after using thyme essential oil for treatment of sore throat and $78.2 \%$ did not notice any side effects. Other type of thyme is the most preferred to be used in general with the highest percentage of $31.6 \%$ followed by Syrian thyme with $28.8 \%$, Palestinian thyme with $21.8 \%$ and lastly Jordanian thyme with $17.8 \%$.

Table 5: General Characteristics ( $\mathrm{N}=500)$

\begin{tabular}{|c|c|c|}
\hline Characteristics & $\begin{array}{c}\text { Frequency } \\
\text { (No.) }\end{array}$ & $\begin{array}{c}\text { Percent } \\
(\%)\end{array}$ \\
\hline \multicolumn{3}{|l|}{ Gender } \\
\hline - Male & 222 & 44.4 \\
\hline - Female & 278 & 55.6 \\
\hline \multicolumn{3}{|l|}{ Age } \\
\hline - $\quad$ Range & $17-65$ & \\
\hline - $\quad$ Mean (Std. Deviation) & 6.21 & \\
\hline \multicolumn{3}{|l|}{ How Often Do You Suffer From } \\
\hline \multicolumn{3}{|l|}{ Sore Throat? } \\
\hline - $\quad$ Always & 19 & 3.8 \\
\hline - $\quad$ Often & 45 & 9 \\
\hline - $\quad$ Sometimes & 130 & 26 \\
\hline - Occasionally & 165 & 33 \\
\hline - Rarely & 141 & 28.2 \\
\hline \multicolumn{3}{|c|}{ Do You Have An Allergy To Antibiotics? } \\
\hline - $\quad$ Yes & 29 & 5.8 \\
\hline - $\quad$ No & 471 & 94.2 \\
\hline \multicolumn{3}{|c|}{ Before Starting, The Course of Antibiotics, } \\
\hline \multicolumn{3}{|c|}{ Did The Doctor Requested You To } \\
\hline \multicolumn{3}{|l|}{ Do Any Test? } \\
\hline - $\quad$ Yes & 139 & 27.8 \\
\hline - $\quad$ No & 361 & 72.2 \\
\hline \multicolumn{3}{|l|}{ Are You Satisfied With The } \\
\hline \multicolumn{3}{|l|}{ Course of Antibiotics? } \\
\hline - $\quad$ Yes & 304 & 60.8 \\
\hline - $\quad$ No & 196 & 39.2 \\
\hline
\end{tabular}

Table 6: General Characteristics ( $\mathrm{N}=500)$

\begin{tabular}{lcc}
\hline $\begin{array}{l}\text { Do You Find Any Side Effects Like } \\
\text { Diarrhea After Administration } \\
\text { of Antibiotics? }\end{array}$ & $\begin{array}{c}\text { Frequency } \\
(\text { No.) }\end{array}$ & $\begin{array}{c}\text { Percent } \\
(\%)\end{array}$ \\
\hline - Yes & 142 & 28.4 \\
- No & 358 & 71.6 \\
After Vaccination Did You Suffer & & \\
From A Sore Throat Infection? & 122 & 24.4 \\
- Yes & 378 & 75.6 \\
- No & & \\
Have You Tried or Thought of Any & & \\
Natural Remedy For Sore Throat? & 346 & 69.2 \\
- Yes & 154 & 30.8 \\
\hline$\quad$ No & & \\
\hline
\end{tabular}

Table 7: General Characteristics About Thyme ( $\mathrm{N}=500)$

\begin{tabular}{lll}
\hline Characteristics & Frequency (No.) & Percent (\%) \\
\hline
\end{tabular}

Have You Tried Using Thyme

Essential oils For Treatment

of Sore Throat?

$\begin{array}{lcc}\text { - Yes } & 82 & 16.4 \\ \text { - No } & 418 & 83.6\end{array}$

Did You Find Any side Effects

After Using Thyme Essential oils

For Treatment of Sore Throat?

- Yes $109 \quad 21.8$

- No $\quad 391 \quad 78.2$

What Type Of Thyme Do You

Prefer To Use In General?

- Syrian Thyme $\quad 144 \quad 28.8$

- Jordanian Thyme $89 \quad 17.8$

- Palestinian Thyme $109 \quad 21.8$

- Other $158 \quad 31.6$

Streptococcus pyogenes is one of the most common pathogen which cause sore throat and it is one of the most difficult infections to be controlled by people around the world. The Middle East population also suffers from seasonal sore throat infections. Many of antimicrobial chemical substances has side effects and physicians prescribe antibiotic without any microbiological test to the patients. After the administration of medication which leads to major complaints such as diarrhea, dysentery and also eradicates the normal flora within the body. To overcome this problem, we thought about ancient medications for sore throat in Middle East regions which is thyme essential oil. As time traveled its usage has vanished and we have attempted to resurrect its's application to treat infections.through ancient traditional methodology of thyme essential oils for the treatment of sore throat which has no side effects. Different types of thyme essential oil were collected and performed a comparative study 
of each thyme essential oils over Streptococcus pyogenes. Thyme essential oil was extracted by boiling and covered to prevent evaporation oil to treat sore throat infection effectively. Prepared the dose of thyme essential oils using $500 \mathrm{~mL}$ of distilled water and $100 \mathrm{~g}$ of different types of thymes at each flask respectively at $100^{\circ} \mathrm{C}$ about an hour and incubated with prepared discs for $24 \mathrm{~h}$ covered by sterile cotton in the incubator. The results were exemplary and found that Jordanian thyme was the most effective type over Streptococcus pyogenes more than Palestinian and Syrian thymes. As we did Kirby Bauer disc diffusion test by soacking the disc overnight and culture the Streptococcus pyogenes on four Mueller Hinton agar. The fourth plate was a comparative study by incorporating all three types of thyme essential oil disc in one agar (Fig.1-2). After 24 $\mathrm{h}$ of incubation, the observation and measurement of the sensitivity reactions on agars were done. Jordanian thyme essential oil had more sensitivity by $31 \mathrm{~mm}$ followed by Palestinian $24 \mathrm{~mm}$ followed by Syrian $16 \mathrm{~mm}$. The Minimum Inhibitory Concentration for each thyme essential oil was performed and observed the values ( Table 2 ) as Jordanian thyme essential oil 1:4 and Palestinian 1:8 and Syrian 1:64 (Fig. 4 to 8 ). To see the efficacy of thyme essential oils on blood agar we did the Minimum Bacterial Concentration and all bacterial grow $>1: 64$ of all types of thyme essential oils. A survey was conducted among a sample of 500 participants to check the awareness about the knowledge about thyme essential oil benefits against antibiotic abuse and its side effects in the Middle East regions (Table 5). About 278 (55.6\%) female and 222 (44.4\%) male occasionally of sore throat infection and big range of them when they visit to doctor to seek medical help, Physicians who didn't perform any test before prescribing the antibiotic $361(72.2 \%)$ in comparison to 139 (27.8\%) Physicians performed the test. The majority of people satisfied with the course of antibiotic $304(60.8 \%)$ and $196(39.2 \%)$ were not. The majority $(94.2 \%)$ of participants were not aware of medication and side effects. The survey about vaccinations we found out 378 (75.6\%) didn't suffer from sore throat, while $122(24.4 \%)$ were not. A large sample of participants tried out natural remedies at home to help them from sore throat infection 346 (69.2\%) and 154 (30.8\%) didn't. A very few of people $82(16.4 \%)$ tried the thyme essential oils and didn't have any side effects on it $391(78.2 \%)$ and we noticed that Syrian thyme had more preferred from people that others two types and 158 (31.6\%) other than thymes essential oils. Further studies may be possible.

The biochemical properties of the different types of thymes used for the study were qualitatively analyzed by using respective versatile biochemical tests and the results observed were interpreted. The biochemical studies of the three thymes reveals the presence of alkaloids, reducing sugar, iodine, steroids and phenols which serves as a major factor in combating the respiratory tract illness.

Table 8: Biochemical test results of each thyme extract

\begin{tabular}{lccc}
\hline Biochemical test & $\begin{array}{c}\text { Syrian } \\
\text { thyme }\end{array}$ & $\begin{array}{c}\text { Jordanian } \\
\text { thyme }\end{array}$ & $\begin{array}{c}\text { Palestinian } \\
\text { thyme }\end{array}$ \\
\hline Fehling's Test & + & + & + \\
lodine Test & + & + & + \\
Salkowski's Test & + & + & + \\
Ferric Test & + & + & + \\
Wagner's Test & + & + & + \\
\hline
\end{tabular}

The Fehling's test showed the appearance of brick red color in al the three thyme extracts indicating the presence of reducing sugar while the lodine Test showed the positive purple color indicating the presence of lodine. A reddish brown color indicating the presence of steroids was Salkowski's test. The blue black coloration which indicating the presence of phenol was determined by Ferric test and the presence of alkaloids in the thyme extract was determined by Wagner's Test where reddish brown precipitate indicates the presence of alkaloids. All the three thyme extracts shown positive test results with the performed biochemical tests. The results observed were recorded and tabulated (Table 7). The presence of phenol in all the thyme extracts indicates its antimicrobial property. The phenolic compound present in the thyme is the major factor in inhibiting the growth of the bacteria by means of cellular lysis which result in the leakage of all the cellular components of the organism along with its virulence factors. The destruction of these types of cellular compounds was performed by the presence of phenols resulting in the disfunctioning of the bacterium. Thus, inhibiting the growth of the bacterium which helps in the decrease of the bacterial load and aborting the infection threshold limit. The biochemical compounds present in the thyme were released through essential oil when the thyme is boiled and when consumed they 
were released in the form of gaseous substances entering the respiratory system. These biochemical substances when released in the gaseous form into the respiratory system plays a potentially significant role in eliminating the pathogens.

\section{CONCLUSION}

The lack of awareness among people about the lack of natural remedies for any infections with zero side effects had proved to be a boost for the pharmaceutical company to boom their industry. However, essential oils such as thyme proved to be an effective alternative therapy for the abuse of antibiotics. The $\mathrm{WHO}$ reports suggest that our time with antibiotics is running out as there are mutant species were reported due to antibiotic abuse. The essential oil extracts from different thyme suggests that this components can be an alternate in the phytopharmaceutical industries to treat different types of infections mor effectively than the available antibiotics ${ }^{17-20}$. This work is a reflection of such factors to save the mankind and will be continued in the future with more relevant research work.

\section{ACKNOWLEDGEMENT}

We would like to Acknowledge Ibn Sina National College, Jeddah, K. S. A., Administration for their constant support and encouragement due to which our project was possible.

\section{Conflict of interests}

No conflict of interest.

\section{REFERENCES}

1. Federspiel P.; Wolkow R.; Zimmermann T., Effects of standardized Myrtol in therapy of acute sinusitis-results of a double-blind, randomized multicenter study compared with placebo. Laryngo-rhino-otologie., 1997, 76(1), 23-27.

2. Schindl VR., Inhalative Wirkung aetherischer Oele. Wien Med Wochenschr., 1972, 122, 591-593.

3. Boyd EM.; Sheppard P., Nutmeg oil and camphene as inhaled expectorants. Archives of Otolaryngology., 1970, 92(4), 372-378.

4. Burrow A.; Eccles R.; Jones AS., The effects of camphor, eucalyptus, and menthol vapor on nasal resistance to airflow and nasal sensation. Acta oto-laryngologica., 1983, 96(1-2), 157-161.

5. Shubina LP.; Siurin SA.; Savchenko VM., Inhalations of Essential oils in the combined treatment of patients with chronic bronchitis. Vrachebnoe delo., 1990, 5, 66-67.

6. Frohlich E., Lavender oil: Review of clinical, pharmacological and bacteriological studies. Contribution to clarification of the mechanism of action. Wiener Medizinische Wochenschrift., 1968, 118, 345-350.

7. Maruzzella JC., The action of perfume-oil vapors on fungi. Am Perfumer Aromat., 1959, 74, 21-22.

8. Maruzzella JC., Sicurella NA. Antibacterial activity of Essential oil vapors. Journal of the American Pharmaceutical Association (Scientific ed.)., 1960, 49(11), 692-694.

9. Kienholz M., On the antibacterial effect of Ethereal oils. Arzneimittel-Forschung., 1959, 9, 519.

10. Pandey DK.; Tripathi NN.; Tripathi RD.; Dixit SN. Fungitoxic and phytotoxic properties of the Essential oil of Hyptis suaveolens/Fungitoxische und phytotoxische Eigenschaften des ätherischen Öis von Hyptis suaveolens. Zeitschrift für Pflanzenkrankheiten und Pflanzenschutz/Journal of Plant Diseases and Protection., 1982, 89, 344-349.

11. Gocho S. Antibacterial action of aroma compounds in vapor state. Int $J$ Antimicrob Agent., 1991, 19, 329-334.

12. Inouye S., Inhibitory effect of volatile constituents of plants on the proliferation of bacteria. Antibacterial activity of plant volatiles. J Antibact Antifungal Agents., 1983, 11, 609-615.

13. Goi H., Antifungal activity of powdery black mustard, powdery wasabi (Japanese Horseradish) and allyl isothiocyanate by gaseous contact. J Antibact Antifungal Agents., 1985, 13(5), 199-204.

14. Gouse BS.; Muazzam SM.; Gokul SS.; Ranjith MS., Isolation and characterization of actinomycetes from soil of ad-dawadmi, Saudi Arabia and screening their antibacterial activities. Int $J$ of Pharm and Pharmaceutical Sc., 2017, 9(10), 267-279. 
15. Muazzam SM.; AlHasel HMB.; Majid DH.; Momen TN.; AlHazmi HAM.; AlJeddani FMS.; AIMalaki RTW.; Khan AA.; Iqubal SMS., Chemical Analysis (GC-FID-MS) and Antimicrobial Activity of Parmotrema perlatum Essential oil Against Clinical Specimens. Orient. J. Chem., 2019, 35(6), 1695-1701.

16. Muazzam SM.; Khan AA.; Tasneem M.; Iqubal SMS.; Shaikh IA.; Muddapur UM.; Sheik GB.; Singh SK.; Hussain MS.; Gamal M., Determination of Antioxidant Properties and Antimicrobial activity of Vinyl Phenolic Compounds Extracted from Saccharomyces cerevisiae Against Uropathogenic Bacteria. Orient. J. Chem., 2020, 36(1), 26-32.

17. Muazzam SM.; Khan AA.; Tasneem M.; Iqubal SMS.; Ikbal AR.; Shaikh IA.; Muddapur UM.; Hussain MS.; Singh SK., The Efficacy of Cinnamomum Tamala As A Potential
Antimicrobial Substance Against The Multi-Drug Resistant Enterococcus Faecalis From Clinical Isolates., Adv Mater Lett., 2020, 11(1), 1-4.

18. Bisht CMS.; Iqubal SMS.; Khan AA.; Tasneem M.; Dawoud A.; Gamal M.; Singh SK.; Asghar $\mathrm{BH}$., Natural Products in Drug Discovery: Antibacterial and Antifungal Activity of Essential oil of Compound Isolated from Senecio royleanus. J Pure Appl Microbio., 2019, 13(3), 1611-1617.

19. Bagewadi ZK.; Muddapur UM.; Madiwal SS.; Mulla SI.; Khan AA., Biochemical and enzyme inhibitory attributes of methanolic leaf extract of Datura inoxia Mill. Environmental Sustainability., 2019, 2, 75-87.

20. Kokate CK.; Purohit AP.; Gokhale SB. Pharmacognosy.; $20^{\text {th }}$ Edn, Nirali prakashan, Pune., 2002, 108-109. 